Hubungan Pengetahuan, Sikap dan Tindakan Ibu dengan Pelaksanaan Inisiasi Menyusui Dini

\title{
The Relationship of Knowledge, Attitude, and Mother Action About the Implementation of Early Breastfeeding Initiation
}

\author{
Titi Saparina L, Rismah \\ Program Studi S1 Kesehatan Masyarakat, Universitas Mandala Waluya \\ (titisaparina.stikesmw @gmail.com, 085253973658)
}

\begin{abstract}
ABSTRAK
Berdasarkan studi pendahuluan yang dilakukan di Puskesmas Anggalomoare menujukkan kunjungan Antenatal Care (ANC) ibu hamil trimester III rata-rata 35 per bulan. Target yang tercapai hanya 62,5\% dari target $85 \%$. Tujuan penelitian ini adalah untuk mengetahui hubungan tingkat pengetahuan, sikap dan tindakan ibu tentang pelaksanaan Inisiasi Menyusui Dini di Puskesmas Anggalomoare. Penelitian ini merupakan penelitian survey dengan pendekatan Cross-Sectional Study. Populasi penelitian ini adalah berjumlah 32 orang dengan penarikan sampel pengambilan sampel dilakukan secara total sampling. Metode analisis menggunakan uji statistik yakni Uji Fisher Exact dan Uji Phi. Hasil penelitian ini menunjukkan bahwa ada hubungan kuat antara pengetahuan ibu dengan pelaksanaan Inisiasi Menyusui Dini ( $\rho$-value $=0,000$; phi $=0,674$ ), ada hubungan sedang antara sikap ibu dengan pelaksanaan Inisiasi Menyusui Dini ( $\rho$-value= 0,002; phi=0,592), ada hubungan cukup kuat antara tindakan ibu dengan pelaksanaan Inisiasi Menyusui Dini ( $\rho$-value $=0,033$; phi=0,516) di Puskesmas Anggalomoare Kabupaten Konawe. Diharapkan bagi pihak puskesmas untuk senantiasa memberikan informasi bagi ibu menyusui maupun ibu hamil mengenai pentingnya pelaksanaan Inisiasi Menyusui Dini. Pemberian informasi dapat diberikan melalui penyuluhan kepada ibu selama hamil, nifas dan saat menyusui anaknya.
\end{abstract}

Kata Kunci: Pengetahuan, sikap, tindakan, inisiasi menyusui dini, puskesmas anggalomoare

ABSTRACT

Based on a preliminary study conducted at the Anggalomoare Public Health Center, it shows that Antenatal Care (ANC) visits for third trimester pregnant women averaged 35 per month. The target achieved was only $62,5 \%$ of the target of $85 \%$. The purpose of this study was to determine the relationship between the level of knowledge, attitudes and actions of mothers regarding the implementation of early breastfeeding initiation at Anggalomoare Public Health Center.This research is a survey research with a cross-sectional Study approach. The population of this study is the total number of pregnant women whose expected day of birth is in February, totaling 32 people. The sampling method was simple total population. The method of analysis used statistical tests, namely the chi square test and the Phi test.The results of this study indicate that there is a strong relationship between maternal knowledge and the implementation of early breastfeeding initiation ( $\rho$-value $=0,000 ;$ phi=0,674), there is a moderate relationship between maternal attitude and implementation of early breastfeeding initiation ( $\rho$-value $=0,002$; phi=0,592), there is a strong enough relationship between maternal actions and implementation early initiation of breastfeeding ( $\rho$-value $=0,033$; phi=0,516) at the Anggalomoare Health Center, Konawe Regency. It is hoped that the Puskesmas will always provide information for breastfeeding mothers and pregnant women about the importance of implementing early breastfeeding initiation. Information can be given through counseling to mothers during pregnancy, postpartum and while breastfeeding their children.

Keywords: Knowledge, attitudes, actions, early breastfeeding initiation, public health center anggalomoare

Article Info:

Received: 23 April $2021 \mid$ Revised form: 3 Juni $2021 \mid$ Accepted: 23 Juni 2021 Published online: 30 Juni 2021 


\section{PENDAHULUAN}

Kematian bayi adalah kematian yang terjadi yang terjadi pada usia bayi baru lahir 0-28 hari (neonatal). Angka kematian bayi yang dilaporkan oleh Word Health Organization (WHO) sangat mengkhawatirkan karena $2 / 3$ dari seleuruh kematian adalah kematian bayi. Kematian neonatal terjadi pada hari pertama kelahiran. Kematian neonatal ini bisa dicegah dengan melakukan IMD (Inisiasi Menyusui Dini). IMD adalah pemberian Air Susu Ibu (ASI) dan menyusui satu jam pertama kehidupan. Kemudian dilanjutkan dengan menyusui ekslusif 6 bulan dapat mencegah kematian bayi. ${ }^{1}$ Dibandingakan dengan negara lain se-Asia Tenggara, Indonesia masih masuk dalam negara yang memiliki Angka Kematian Bayi (AKB) yang tinggi. Dimana menurut laporan Human Development Report 2010, AKB di Indonesia mencapai 32/1000 kelahiran, yang menunjukkan persentase 5,2\% lebih besar daripada Malaysia, 1,2\% lebih besar daripada Filipina, dan 2,4\% lebi besar daripada Thailand. ${ }^{2}$

Berdasarkan data nasional menurut SDKI tahun 2012 yang dikeluarkan oleh Kemenkes RI tahun 2013, AKB mengalami penurunan seak tahun 1999 hingga 2012. Pada tahun 1999 AKB sebanyak 46 per 1000 kelahiran hidup, 2002-2003 sebanyak 35 per 1000 kelahiran hidup, tahun 2007 sebayak 34 per 1000 kelahiran hidup dan tahun 2012 sebanyak 32 per 1000 kelahiran hidup. Meskipun demikian, Angka Kematian Bayi belum mengalami penurunan yang signifikan. Hal ini karena besaran angka tersebut belum mewakili situasi di beberapa wilayah di Indonesia yang sebenarnya, karena adanya kesenjangan yang sangat jauh antara kota besar dan kota kecil, antara wilayah barat dan wilayah timur Indonesia. serta antara urban dan rural. Selain itu, parahnya lagi tidak semua kematian bayi tercatat di puskesmas. ${ }^{3}$

Inisiasi Menyusui Dini (IMD) diawali dengan adanya kontak fisik dalam hal ini kulit antara ibu dan bayi yang baru lahir lalu dilanjutkan dengan pemberian ASI. IMD merupakan salah satu program yang digagas oleh pemerintah Indonesia sabaga upaya memaksimalkan pelaksanaan pemberian ASI eksklusif sebagai bagian manajemen laktasi. ${ }^{4}$ Data nasional menujukkan persentase bayi yang diberi perlakukan IMD hanya sebesar 29,3\%. Data yang lebih rendah dari data nasional tersebut dietmukan di Sulawesi Tengara yakni $27,6 \% .^{5}$

Terdapat beberapa faktor ditemukan yang menjadi hal yang mempengaruhi pelaksanaan Inisiasi Menyusui Dini (IMD). Faktor tersbut ada yang berupa faktor internal juga faktor eksternal. Faktor internal diantaranya pengetahuan dan sikap ibu. Sementara faktor ekstrenal diantaranya dukungan dari suami, keluarga dan orang-orang terdekat, serta dukungan dari petugas kesehatan seperti dokter dan bidan. Faktor-faktor tersebutlah yang kerap memberikan sumbangsih terhadap pelaksanaan IMD. Penelitian Karen Edmond dkk melaporkan bahwa IMD pada jam pertama setelah lahir mampu mengurangi risiko kematian bayi sebesar 22\% pada bayi yang berumur 0-28 hari. Sebaliknya, keterlambatan IMD dapat memperbesar risiko kematian hingga 2,4 kali. Disamping itu, dengan pelaksanaan IMD, bayi dan ibu tidak segera dipisahkan setelah bayi lahir. ${ }^{6}$ Menurut dr. Radix Hadriyanto SpA dari Rumah 
Sakit Adi Husada, Jika tidak segera melaksanakan IMD, maka menyebabkan 50\% kemampuan bayi untuk menyusui berkurang. Bayi yang tidak dapat menyusui juga terjadi pada bayi lahir normal yang dipisahkan dari ibunya yang tidak langsung disusui oleh ibunya. Selain itu juga dikarenakan bayi yang lahir dengan bantuan tindakan atau obat-obatan yang langsung dipisahkan dari ibunya.

Hal tersebut membuktikan besarnya pengaruh kontak fisik ibu dan bayi pasca dilahirkan untuk proses selanjutnya. $^{7}$

Berdasarkan studi pendahuluan yang dilakukan di Puskesmas Anggalomoare pada tanggal 20 Oktober 2019 menujukkan kunjungan Antenatal Care (ANC) ibu hamil trimester III ratarata 35 per bulan. Setelah dilakukan pengkajian, diketahui $30 \%$ ibu hamil trimester III belum mengetahui secara mendalam tentang Inisiasi Menyusui Dini. Sementara target yang tercapai hanya $45 \%$ dari target $85 \%$ yang diharapkan pihak puskesmas. Lebih lanjut peneliti melakukan studi pendahuluan di wilayah Puskesmas Anggalomoare pada bulan Oktober, pada pengamatan yang dilakukan peneliti sebelumnya melalui pertanyaan langsung mengenai setelah berapa jam melahirkan ibu harus menyusui bayinya kepada 3 ibu bersalin, hanya 1 orang yang menjawab segera setelah lahir, sedangkan 2 orang menjawab tidak tahu. Berdasarkan beberapa fenomena tersebut maka peneliti merasa tertarik untuk mengadakan penelitian tentang "Hubungan Pengetahuan, Sikap dan Tindakan Ibu tentang Pelaksanaan Inisiasi Menyusui Dini di Puskesmas Anggalomoare”.

\section{BAHAN DAN METODE}

Metode penelitian ini menggunakan analitik observasional dengan rancangan cross-sectional study yang dilaksanakan bulan April 2020 di Puskesmas Anggalomoare. Populasi penelitian adalah semua ibu hamil yang tercatat pada bulan Februari berjumlah 32 orang dan sampel juga 32 responden dengan teknik pengambilan sampel menggunakan total sampling. Pengumpulan data menggunakan data primer dan data sekunder. Instrumen penelitian menggunakan lembar kuisioner. Data diolah menggunakan SPSS 16.0 dengan analisis univariat dan analisis bivariat dengan Uji Fisher Exact dan lanjutkan dengan Uji Phi. Data disajikan dalam bentuk tabel distribusi serta tabel analisis pengaruh antara variabel, yang disertai dengan narasi.

\section{HASIL}

Distribusi responden berdasarkan pendidikan di Puskesmas Anggalomoare Tahun 2020 pada Tabel 1.

Tabel 1. Distribusi Karakteristik Responden Di Puskesmas Anggalomoare

\begin{tabular}{ccc}
\hline Karateristik & N (32) & \% \\
\hline Pendidikan & & \\
Tamatan SD & 4 & 12,5 \\
Tamatan SMP & 9 & 28,1 \\
Tamatan SMA & 14 & 43,8 \\
Perguruan tinggi & 5 & 15,6 \\
\hline Umur (Tahun) & & \\
$>$ 25 & 13 & 40,6 \\
$<25$ & 19 & 59,4 \\
\hline Pekerjaan & & \\
IRT & 12 & 37,5 \\
Petani & 16 & 50,0 \\
PNS & 4 & 12,5 \\
\hline Total & $\mathbf{3 2}$ & $\mathbf{1 0 0}$ \\
\hline
\end{tabular}

Sumber: Data Primer, 2020 
Tabel 1 menunjukan pendidikan terbanyak terdapat pada tamatan SMA sebanyak 14 responden $(43,8 \%)$ dan paling sedikit pada tamatan SD sebanyak 4 responden (12,5\%). Distribusi responden berdasarkan umur di Puskesmas Anggalomoare tahun 2020 didominasi oleh kelompok umur >25 tahun sebanyak 13 responden (40,6\%). Distribusi responden berdasarkan pekerjaan di Puskesmas Anggalomoare tahun 2020 pekerjaan terbanyak pada petani sebanyak 16 responden $(50,0 \%)$, dan pada yang sedikit pada PNS sebanyak 4 responden $(12,5 \%)$.

Distribusi responden berdasarkan pelaksanaan Inisiasi Menyusui Dini dapat dilihat pada Tabel 2.

Tabel 2. Distribusi Frekuensi berdasarkan Inisiasi Menyusui Dini, Pengetahuan, Sikap, dan Tindakan Ibu di Puskemas Anggalomoare

\begin{tabular}{lrr}
\hline \multirow{2}{*}{ Variabel } & \multicolumn{2}{c}{ Total } \\
\cline { 2 - 3 } Inisiasi Menyusui & $\mathbf{N}$ & $\mathbf{\%}$ \\
Dini & & \\
Melakukan & 20 & 62,5 \\
Tidak Melakukan & 12 & 37,5 \\
Total & $\mathbf{3 2}$ & 100 \\
\hline Pengetahuan & & \\
Cukup & 19 & 59,4 \\
Kurang & 13 & 40,6 \\
Total & $\mathbf{3 2}$ & 100 \\
\hline Sikap & & \\
Cukup & 22 & 68,8 \\
Kurang & 10 & 31,2 \\
Total & $\mathbf{3 2}$ & 100 \\
\hline Tindakan & & \\
Cukup & 16 & 50,0 \\
Kurang & 16 & 50,0 \\
Total & $\mathbf{3 2}$ & 100 \\
\hline Sumber: Data Primer, 2020 & &
\end{tabular}

Hasil penelitian menunjukkan bahwa jumlah responden yang melakukan Inisiasi Menyusui Dini sebanyak 20 orang $(62,5 \%)$ dan yang tidak melakukan Inisiasi Menyusui Dini sebanyak 12 orang $(37,5 \%)$. Distribusi responden berdasarkan pengetahuan menunjukan hasil bahwa responden yang pengetahuan cukup sebanyak 19 orang $(59,4 \%)$ dan yang pengetahuannya kurang sebanyak 13 orang $(40,6 \%)$. Distribusi responden berdasarkan sikap menunjukkan bahwa responden yang sikapnya cukup sebanyak 22 orang $(68,8 \%)$ dan yang sikapnya kurang sebanyak 10 orang (31,2\%). Distribusi responden berdasarkan tindakan menunjukkan bahwa jumlah responden tindakannya cukup sebanyak 16 orang $(50,0 \%)$ dan yang tindakannya kurang sebanyak 16 orang $(50,0 \%)$.

Adapun hubungan variabel pengetahuan ibu tentang pelaksanaan Inisiasi Menyusui Dini di Puskesmas Anggalomoare tahun 2020 dapat dilihat pada Tabel 3. Pada Tabel 3 menunjukan bahwa dari total 19 responden pengetahuan cukup, yang melakukanan sebanyak 17 reponden $(53,1 \%)$ dan yang tidak melakukan Inisiasi Menyusui Dini sebanyak 2 responden $(6,2 \%)$. Sedangkan dari 13 responden pengetahuan kurang yang melakukan 3 responden $(9,4 \%)$ dan tidak melakukan Inisiasi Menyusui Dini sebanyak 10 responden $(31,2 \%)$. Hasil nilai uji statistik diperoleh nilai hasil Uji Fisher Exact Test $(\rho$-value $=0,000<$ nilai $\alpha=0,05)$ artinya ada hubungan antara pengetahuan ibu tentang pelaksanaan Inisiasi Menyusui Dini di Puskesmas Anggalomoare tahun 2020. Kemudian berdasarkan uji keeratan hubungan diperoleh nilai $p h i=0,674$, artinya ada hubungan kuat antara kedua variabel. 
Untuk hubungan variabel sikap ibu tentang pelaksanaan Inisiasi Menyusui Dini di Puskesmas Anggalomoare Tahun 2020 dapat dilihat pada Tabel 3. Pada Tabel 3 menunjukkan bahwa dari total 22 responden pengetahuan cukup, yang melakukan sebanyak 18 reponden $(56,2 \%)$ dan yang tidak melakukan Inisiasi Menyusui Dini sebanyak 4 responden (12,5\%). Sedangkan dari 10 responden pengetahuan kurang yang melakukan 2 responden $(6,3 \%)$ dan tidak melakukan Inisiasi
Menyusui Dini sebanyak 8 responden $(25,0 \%)$. Hasil nilai uji statistik diperoleh nilai hasil Fisher Exact Test $(\rho)=0,002<(\alpha) 0,05$, maka $\mathrm{H}_{\mathrm{o}}$ ditolak dan $\mathrm{H}_{\mathrm{a}}$ diterima artinya berarti ada hubungan antara sikap ibu tentang pelaksanaan Inisiasi Menyusui Dini di Puskesmas Anggalomoare tahun 2020. Kemudian berdasarkan uji keeratan hubungan diperoleh nilai phi=0,592, artinya ada hubungan cukup kuat antara kedua variabel.

Tabel 3. Analisis Hubungan Pengetahuan, Sikap, Tindakan Ibu terhadap Inisiasi Menyusui Dini di Puskesmas Anggalomoare

\begin{tabular}{|c|c|c|c|c|c|c|c|}
\hline \multirow{3}{*}{ Variabel } & \multicolumn{4}{|c|}{ Inisiasi Menyusui Dini } & \multirow{2}{*}{\multicolumn{2}{|c|}{ Total }} & \multirow{3}{*}{ Hasil Uji Statistik } \\
\hline & \multicolumn{2}{|c|}{ Melakukan } & \multicolumn{2}{|c|}{$\begin{array}{c}\text { Tidak } \\
\text { melakukan }\end{array}$} & & & \\
\hline & $\mathbf{n}$ & $\%$ & n & $\%$ & $\mathbf{N}$ & $\%$ & \\
\hline \multicolumn{8}{|l|}{ Pengetahuan } \\
\hline Cukup & 17 & 53,1 & 2 & 6,2 & 17 & 59,4 & Fisher Exact Test \\
\hline Kurang & 3 & 9,4 & 10 & 31,2 & 13 & 40,6 & $\rho$-value $=0,000$ \\
\hline Total & 20 & 62,5 & 12 & 37,5 & 32 & 100 & $P h i=0,674$ \\
\hline \multicolumn{8}{|l|}{ Sikap } \\
\hline Cukup & 18 & 56,2 & 4 & 12,5 & 22 & 68,8 & Fisher Exact Test \\
\hline Kurang & 2 & 6,3 & 8 & 25,0 & 10 & 31,2 & $\rho$-value $=0,002$ \\
\hline Total & 20 & 62,5 & 12 & 37,5 & 32 & 100 & $P h i=0,592$ \\
\hline \multicolumn{8}{|l|}{ Tindakan } \\
\hline Cukup & 14 & 43,8 & 2 & 6,3 & 16 & 50 & Fisher Exact Test \\
\hline Kurang & 6 & 18,7 & 10 & 31,2 & 16 & 50 & $\rho$-value $=0,033$ \\
\hline Total & 20 & 62,5 & 12 & 37,5 & 32 & 100 & $P h i=0,516$ \\
\hline
\end{tabular}

Sumber: Data Primer, 2020

Adapun hubungan variabel tindakan ibu tentang Inisiasi Menyusui Dini di Puskesmas Anggalomoare tahun 2020 dapat dilihat pada Tabel 3. Pada Tabel 3 menunjukkan bahwa dari total 16 responden pengetahuan cukup, yang melakukan sebanyak 14 reponden $(43,8 \%)$ dan yang tidak melakukan Inisiasi Menyusui Dini sebanyak 2 responden $(6,3 \%)$. Sedangkan dari 16 responden pengetahuan kurang yang melakukan 6 responden $(18,7 \%)$ dan tidak melakukan Inisiasi Menyusui Dini sebanyak 10 responden (31,2\%). Hasil nilai uji statistik diperoleh nilai Fisher Exact Test $(\rho)=0,033<(\alpha) 0,05$, artinya ada hubungan antara tindakan ibu tentang pelaksanaan Inisiasi Menyusui Dini di Puskesmas Anggalomoare tahun 2020. Kemudian berdasarkan uji keeratan 
hubungan diperoleh nilai phi $=0,516$, artinya ada hubungan cukup kuat antara kedua variabel.

\section{PEMBAHASAN}

Pengetahuan mengenai Inisiasi Menyusui Dini dapat menjadi bekal bagi ibu hamil untuk melakukan persiapan baik secara fisik maupun psikisnya kelak saat menghadapi proses persalinan untuk melaksanakan Inisiasi Menyusui Dini. Hasil penelitian menunjukkan bahwa dari total 19 responden yang pengetahuan cukup tetapi tidak melakukan Inisiasi Menyusui Dini sebanyak 2 responden (6,2\%). Kondisi tersebut terjadi karena minimnya pengetahuan responden terkait pelaksanaan Inisiasi Menyusui Dini, dimana responden hanya tahu tetapi tidak memahami lebih jauh terkait pelaksanaan Inisiasi Menyusui Dini. Berdasarkan hasil wawancara, responden yang memiliki pengetahuan baik sebagiannya hanya tahu kalau Inisiasi Menyusui Dini hanya memberikan ASI saat bayi lahir, tanpa tahu maksudnya kalau Inisiasi Menyusui Dini bisa menurunkan 22\% kematian 28 hari. Disamping itu, walaupun pengetahuan ibu cukup akan tetapi pelaksanaannya belum optimal disebabkan kurangnya dukungan dan kesadaran penuh dari petugas medis yang menolong persalinan sehingga Inisiasi Menyusui Dini tidak dilaksanakan. Sehingga peran dan dukungan bidan merupakan salah satu faktor penunjang terlaksananya Inisiasi Menyusui Dini . ${ }^{8}$

Pengetahuan bukan merupakan satu-satunya faktor yang menyebabkan terlaksannya Inisiasi Menyusui Dini, akan tetapi dipengaruhi oleh faktor lain seperti kurangnya dukungan bidan ataupun dukungan suami kepada responden. Begitu pula dengan yang memiliki pengetahuan cukup dan kurang tetapi banyak yang melaksanakan Inisiasi Menyusui Dini. Hal ini disebabkan karena pengetahuan cukup dan kurang juga bukan salah satu faktor penghambat terlaksananya Inisiasi Menyusui Dini, walaupum tidak memiliki pengetahuan luas tetapi adanya dorongan suami dan dorongan bidan sebelum proses persalinan, terlebih dahulu menjelaskan bahwa betapa pentingnya proses Inisiasi Menyusui Dini dilaksanakan yang dapat membantu bayi menyusui selama 6 bulan agar bayi terhindar dari segala penyakit. ${ }^{9}$ Pengetahuan seseorang bisa dipengaruhi oleh adanya paparan informasi dari media massa baik media elektornik maupun media cetak. Selain itu informasi yang didapatkan baik dari pendidikan formal maupun non formal dapat membawa pengaruh jangka pendek yang bisa membawa perubahan pengetahuan. Ternyata hampir semua ibu menganggap bahwa bayi tidak akan bisa ditengkurapkan ke dada ibunya adan langsung mencari sendiri puting ibunya untuk menyusui. Hal tersebut yang menyebabkan mereka tidak mau menerapkan Inisiasi Menyusui Dini ${ }^{10}$

Sedangkan dari total 13 responden pengetahuan kurang yang melakukan Inisiasi Menyusui Dini 3 responden $(9,4 \%)$ hal ini disebabkan karena pengetahuan mengenai Inisiasi Menyusui Dini yang diperoleh ibu ketika pelaksanan posyandu. Namun, penyuluhan tentang Inisiasi Menyusui Dini tidak dilakukan oleh seluruh posyandu di wilayah kerja Puskesmas Anggalomoare. Bidan yang bertanggung jawab melaksanakan penyuluhan pada saat kegiatan 
posyandu tersebut. Jadi, penyuluhan dilakukan di posyandu, bergantung pada bidan yang bertanggung jawab pada posyandu tersebut. Selain itu menurut penelitian lain yang mengatakan bahwa suatu tindakan bermula dari pengetahuan yang dipersepsikan sebagai suatu hal yang positif maupun negatif, kemudian diinternalisasikan ke dalam dirinya. Dari apa yang diketahuinya akan mempengaruhi pada tindakannya. Jika yang dipersepsikan tersebut bersifat positif maka seseorang cenderung berperilaku sesuai dengan persepsinya sebab setuju dengan apa yang diketahuinya, dan sebaliknya jika seseorang mempersepsikan negatif maka cenderung menghindari atau tidak melakukan hal tersebut. ${ }^{11}$

Ibu dengan pengetahuan cukup pada umumnya tidak mempunyai kendala dalam proses menyusui karena para ibu memahami tentang manfaat menyusui dini dan cara menyusui yang benar. Sedangkan responden dengan pengetahuan kurang masih mempunyai kendala dalam hal menyusui dini karena masih ada ibu-ibu yang belum mengetahui tentang keunggulan menyusui dini, cara menyusui dan kurangnya dukungan dari keluarga atau suami agar ibu mau melakukan Inisiasi Menyusui Dini. Penelitian ini sejalan dengan penelitian lain yang menyatakan bahwa ada hubungan yang bermakna antara pengetahuan ibu dengan pelaksanaan Inisiasi Menyusui Dini dengan nilai uji $P h i=0,415$ yang berarti semakin baik pengetahuan ibu maka semakin baik pula dalam pelaksanaan Inisiasi Menyusui Dini. ${ }^{12}$ Penelitian serupa juga menemukan bahwa responden dengan pengetahuan kurang yang tidak memberikan ASI eksklusif, yang dikaitkan dengan karakteristik responden berusia 20-30 tahun, hal ini merupakan golongan umur dewasa awal yang cenderung kurang memiliki pengalaman sehingga pengetahuannya kurang, berkaitan dengan pendidikan yang rendah yaitu SD dan SMP yang pengetahuannnya kurang sehingga dapat menjadi penyebab kurangnya pengetahuan tentang pemberian ASI eksklusif. ${ }^{13}$

Sikap tidak dapat langsung dilihat, tetapi hanya dapat ditafsirkan terlebih dahulu dari perilaku yang tertutup. ${ }^{14}$ Hasil penelitian menunjukkan bahwa dari total 22 responden memiliki sikap cukup namun terdapat $12,5 \%$ responden tidak menerapkan Inisiasi Menyusui Dini. Hal ini disebabkan karena pelaksanaan Inisiasi Menyusui Dini yang berhasil atau pun gagal tergantung oleh beberapa faktor antara lain tidak adanya motivasi dari diri sendiri untuk melaksanakan Inisiasi Menyusui Dini. Selain itu kelelahan yang juga dirasakan repsonden setelah melalui proses persalinan, ditambah rasa sakit yang timbul pasca melahirkan menyebabkan responden merasa kurang nyaman melakukan Inisiasi Menyusui Dini dan akhirnya responden ingin cepat-cepat menyelesaikan proses persalinan lalu berpindah ke kamar perawatan puskesmas. Bersikap positif cenderung mendorong orang tersebut untuk berperilaku positif disetiap aspek kehidupan dan sebaliknya seseorang yang bersikap negatif cenderung mendorong orang tersebut untuk berperilaku negatif. Maka semakin baik sikap ibu nifas maka semakin tinggi pula kesadaran ibu nifas untuk melaksanakan Inisiasi Menyusui Dini dan pada ibu nifas yang memiliki 
sikap negatif cenderung untuk tidak melaksanakan Inisiasi Menyusui Dini.

Sedangkan dari 10 responden memiliki sikap kurang tetapi melaksakan Inisiasi Menyusui Dini. Hal ini terjadi karena sikap ibu bukan merupakan penghambat pelaksanaan Inisiasi Menyusui Dini akan tetapi adanya dukungan dari keluarga/suami yang mengetahui betapa pentingnya manfaat Inisiasi Menyusui Dini terhadap bayi baru lahir sehingga keluarga/suami menyarankan ibu melaksanakan Inisiasi Menyusui Dini. Menurut Notoatmodjo yang menyatakan sikap adalah reaksi atau respon yang masih tertutup dari seseorang terhadap stimulus atau objek. Sikap tidak bisa dilihat secara langsung, namun hanya dapat ditafsirkan dahulu dari perilaku yang tertutup. Hal tersebut dibuktikan dari sikap sebagian besar ibu memiliki sikap buruk yang berasal dari pengetahuan yang kurang tentang Inisiasi Menyusui Dini. Adapun kurangnya pengetahuan dipengaruhi oleh kurangnya informasi diperoleh terkait Inisiasi Menyusui Dini. Kondisi tersebut sesuai dengan pendapat Wawor dkk bahwa salah satu faktor yang mempengaruhi sikap seseorang terhadap suatu objek yakni media massa. Selain faktor pengetahuan, sikap negatif ibu mengenai Inisiasi Menyusui Dini disebabkan karena kepercayaan mereka yang kurang terhadap kurang terhadap Inisiasi Menyusui Dini. ${ }^{15}$ Hal ini menunjukan bahwa mereka beranggapan bahwa melakukan Inisiasi Menyusui Dini penting bagi bayi karena bisa mencerdaskan otak dan mempercepat pertumbuhan selain bisa mengurangi pengeluaran keluarga. Menyusui menurut mereka juga dapat mempererat kasih sayang antara ibu dan anak. Penelitian ini didukung oleh hasil penelitian Hargi yang menemukan bahwa terdapat hubungan antara sikap dengan praktik IMD pada ibu setelah melahirkan dengan nilai uji Phi=0,314. ${ }^{16}$

Sikap akan terwujud menjadi perbuatan yang rill jika ada faktor penting yang mendukung tindakan yang akan dilakukan dalam pelaksanaan Inisiasi Menyusui Dini. Hasil penelitian menunjukkan bahwa dari total 16 responden yang tindakan cukup tetapi tidak melaksanakan Inisiasi Menyusui Dini sebanyak 2 responden $(6,2 \%)$ hal ini disebabkan karena kurangnya dukungan suami atau keluarga agar meningkatkan rasa percaya diri ibu dan alasan lainnya karena faktor fisik ibu dimana kondisi fisik ibu masih lemah dan ASInya tidak lancar sehingga bayi tidak diberikan ASI sampai hari kedua pasca persalinan, Selain itu responden juga mengatakan bahwa anak cukup di berikan susu formula yang gizinya cukup tinggi untuk memenuhi kebutuhan anaknya. Keadaan ini juga disebabkan oleh faktor Pekerjaan ibu dimana terdapat 4 responden $(12,5 \%)$ adalah PNS, Ibu yang memiliki pekerjaaan memiliki pikiran yang terbagi antara merawat diri dan bayinya dan memikirkan pekerjaannya. Hal ini menyebabkan ibu lupa melakukan Inisiasi Menyusui Dini. Penelitian ini sejalan dengan teori yang dikemukakan oleh Prasetyawati bahwa tindakan adalah respon nyata ibu terkait pemberian ASI yakni upaya ibu dapat memberikan kolostrum yang pertama keluar pada bayinya. Tindakan merupakan proyeksi dari pengetahuan dan sikap, sehingga diaplikasikan dalam bentuk tindakan. Pada umumnya seseorang yang pengetahuannya 
dan sikapnya baik maka tindakannya akan baik, demikian pula sebaliknya seseorang yang pengetahuan dan sikapnya kurang, maka akan berdampak pada tindakannya. Kekebalan bayi akan bertambah dengan adanya kandungan zat-zat dan vitamin yang terdapat pada air susu ibu tersebut, serta volume kolostrum yang meningkat dan ditambah dengan adanya isapan bayi baru lahir secara terus menerus. ${ }^{17}$

Sedangkan dari total 16 responden yang tindakan kurang tetapi melakukan Inisiasi Menyusui Dini sebanyak 6 responden $(18,8 \%)$ hal ini disebabkan karena adanya dukungan dari bidan yaitu pada saat melahirkan bayi langsung diletakkan di bagian dada ibu oleh bidan sehingga bayi mencari puting ibu untuk menyusui. Hal ini karen ibu merasa capek dan kelelahan saat melahirkan sehingga meskipun ibu tidak melakukan tindakan Inisiasi Menyusui Dini tapi karena adanya bantuan dari bidan. Rendahnya tindakan disebabkan oleh kurangnya pengetahuan dan sikap ibu sehingga berdampak pada tindakannya. Tindakan merupakan proyeksi pengetahuan dan sikap sehingga semakin kurang pengetahuan dan sikap ibu makan tindakannya pun semakin kurang. Ada hubungan cukup kuat antara kedua variabel. Ini meunjukan bahwa perlu ada dukungan bidan dan keluarga pada saat persalinan sehingga dapat memberikan penjelasan kepada ibu tentang manfaat menyusui dini, mendukung ibu untuk mau menyusui bayinya dalam waktu 30 menit setelah pesalinan yang dilakukan di kamar bersalin, hanya memberika ASI kepada bayi baru lahir tanpa makanan atau minuman tambahan apa pun, mengupayakan perawatan sekamar agi bayi dan ibu adar tetap bersama selama 24 jam sehari, dan tidak memberikan dot kepada bayi yang diberi ASI. Penelitian ini sejalan dengan penelitian yang dilakukan oleh Wiradinata menunjukkan bahwa tindakan merupakan faktor yang mempengaruhi rendahnya pelaksanaan inisisasi menyusui dini pada bayi baru lahir. ${ }^{18}$

\section{KESIMPULAN DAN SARAN}

Sesuai dengan hasil penelitian yang dilakukan, maka dapat disimpulkan bahwa ada hubungan kuat antara pengetahuan ibu tentang pelaksanaan Inisiasi Menyusui; ada hubungan cukup kuat antara sikap ibu tentang pelaksanaan Inisiasi Menyusui Dini, dan ada hubungan cukup kuat antara tindakan ibu tentang pelaksanaan Inisiasi Menyusui Dini di Puskesmas Anggalomoare Tahun 2020. Diharapkan bagi institusi pelayanan dan institusi lainnya agar memberikan penyuluhan terhadap faktor yang berhubungan dengan pelaksanaan Inisiasi Menyusui Dini kepada ibu hamil yang berkunjung di Puskesmas Anggalomoare agar dapat meningkatkan pengetahuannya. Diharapkan kepada keluarga/suami agar jangan hanya memeriksa kehamilannya saja tetapi juga segera menambah pengetahuannya tentang IMD. Diharapkan agar mencari informasi tentang IMD melalui media cetak, elektronik dan petugas kesehatan demi peningkatan pengetahuan terkait IMD. Diharapkan pula bagi peneliti selanjutnya agar melakukan penelitian selanjutnya dengan variabel dukungan keluarga dan faktor budaya. 


\section{UCAPAN TERIMA KASIH}

Ucapan Terima kasih diberikan kepada Ketua Yayasan Mandala Waluya dan pihak Puskesmas Anggalomoare yang telah mendukung pelaksanaan penelitian ini.

\section{DAFTAR PUSTAKA}

1. Yusnita. Faktor-faktor yang Berhubungan dengan Pelaksanaan Inisiasi Menyusui Dini (IMD) di Wilayah Kerja Puskesmas Abeli Kota Kendari Tahun 2013 [Skripsi]. [Kendari]: STIKes Mandala Waluya; 2014.

2. Prasetyawati. Buku Pintar ASI Eksklusif, Pengenalan Praktek dan Kemanfaatannya. 1 ed. Yogyakarta: Diva Press; 2015.

3. Kementerian Kesehatan RI. Strategi Nasional Peningkatan Air Susu Ibu (PPASI). Jakarta; 2015.

4. Kementerian Kesehatan RI. Menyusui 1000 Hari Pertama Periode Emas Kehidupan Bayi. Jakarta; 2017.

5. Kementerian Kesehatan RI. Profil Kesehatan Indonesia Tahun 2017. Jakarta; 2018.

6. Edmond KM, Quigley MA, Etego SA, Agyei SO, Kirkwood BR. Delayed Breastfeeding Initiation Increases Risk of Neonatal Mortality. Pediatrics. 2016;117(3).

7. Rahmawati MD. Faktor-Faktor yang Mempengaruhi Pemberian Asi Eksklusif pada Ibu Menyusui di Kelurahan Pedalangan Kecamatan Banyumanik Kota Semarang. J KesMaDaSKa. 2015;1(1):8-17.

8. Jatmaika SED, Shaluhiyah Z, Suryoputro A. Dukungan Tenaga Kesehatan untuk Meningkatkan Niat Ibu Hamil dalam
Memberikan ASI Eksklusif di Wilayah Kerja Puskesmas Gondokusuman, Kota Yogyakarta. J Promosi Kesehat Indones. 2016;9(2):196205.

9. Jannah AM. Faktor - Faktor Yang Berhubungan Dengan Perilaku Pemberian Asi Eksklusif Pada Bayi Usia 6 - 12 Bulan Di Kelurahan Gerem Wilayah Kerja Puskesmas Grogol Kota Cilegon Tahun 2015 [Skripsi]. [Jakarta]: Universitas Islam Negeri Syarif Hidayatullah Jakarta; 2016.

10. Destyana RM, Angkasa D, Nuzrina R. Hubungan Peran Keluarga dan Pengetahuan Ibu Terhadap Pemberian ASI di Desa Tanah Merah Kabupaten Tangerang Destyana, R.M., D. Angkasa., dan R. Nuzrina. Indones J Huma Nutr. 2018;5(1):41-50.

11. Hargono R, Kurniawati D. Faktor Determinan yang Mempengaruhi Kegagalan Pemberian ASI Eksklusif pada Bayi Usia 6-12 Bulan di Kelurahan Mulyorejo Wilayah Kerja Puskesmas Mulyorejo Surabaya. J Promosi Kesehat Indones. 2014;2(1):15-27.

12. Ulandari D. Faktor-faktor yang Berhubungan Dengan Pelaksanaan Inisiasi Menyusui Dini oleh Bidan Praktek Swasta di Kota Palembang tahun 2012. J Kebidanan. 2012;2(1):21-9.

13. Nangi MG. Faktor-Faktor yang Berhubungan dengan Pemberian Air Susu Ibu Eksklusif di Wilayah Kerja Puskesmas Anggalomoare Kabupaten Konawe. J MediLab Mandala Waluya. 2019;3(1):87-96.

14. Notoatmodjo. Pendidikan dan Perilaku Kesehatan. Jakarta: Rineka Cipta; 2013. 
15. Wowor M, Laoh JM, Pangemanan DHC. Hubungan Pengetahuan dan Sikap dengan Pemberian ASI Eksklusif pada Ibu Menyusui di Puskesmas Bahu Kota Manado. E-J Keperawatan. 2013;1(1):1-7.

16. Hargi JP. Hubungan Dukungan Suami dengan Sikap Ibu Dalam Pemberian ASI Eksklusif di Wilayah Kerja Puskesmas Arjasa Kabupaten Jember [Skripsi]. [Jember]: Universitas Jember; 2013.

17. Fikawati S, Syafiq A. Kajian Implementasi dan Kebijakan Air Susu Ibu Eksklusif dan Inisiasi Menyusui Dini di Indonesia. Makara Kesehat. 2010;14(1):17-24.

18. Mardiananingsih. Perbandingan Pelaksanaan Inisiasi Menyusui Dini Berdasar Tingkat Pengetahuan Ibu Hamil [Skripsi]. [Kendari]: STIKes Mandala Waluya; 2008. 